\title{
Serum concentrations of Helicobacter pylori IgG and the virulence factor CagA in patients with ischaemic heart disease
}

A. Jafarzadeh, ${ }^{1}$ A. Esmaeeli-Nadimi, ${ }^{2}$ M. Nemati, ${ }^{1}$ M. Tahmasbi ${ }^{2}$ and P. Ahmadi ${ }^{1}$

$$
\begin{aligned}
& \text { التـر اكيز المصلية للغلوبولين المناعي "الأيج -ج)" المضاد للمَّلْيَّات البوَّابية ولعامها الفوعي CagA في المصابين بمرض القلب } \\
& \text { الإقفاري } \\
& \text { عبد الله جعفرز اده، علي إسماعيلي نديمي، مريم نعمتي، مريم طهاسبي، برديس أحمدي }
\end{aligned}
$$

ABSTRACT To compare the serum concentrations of IgG to Helicobacter pylori and its virulence factor CagA in patients with ischaemic heart disease (IHD), we recruited 120 patients with IHD [acute myocardial infarction (AMI) $(n=60)$; unstable angina (UA) $(n=60)]$ and 60 sex- and age-matched healthy controls in this study. The seroprevalence of anti-H. pylori IgG was $86.7 \%$ in AMI, $91.7 \%$ in UA patients and $58.3 \%$ in the control group with mean titres of $33.2 \mathrm{U} / \mathrm{ml}$ [standard error (SE) 4.76], 57.96 U/ml (SE 7.54) and 25.72 U/ml (SE 4.01) respectively. The seroprevalence of anti-H. pylori in the patient groups was significantly higher than the control group. The mean levels of anti-H. pylori in the AMI and UA groups were also significantly higher than in the control group. The seroprevalence and mean titre of anti-CagA IgG did not differ significantly between patient and control groups.

\section{Concentrations sériques d'IgG anti-Helicobacter pylori et facteur de virulence CagA chez les patients souffrant de cardiopathie ischémique}

RÉSUMÉ Afin de comparer les concentrations sériques de I'IgG anti-Helicobacter pylori et son facteur de virulence CagA chez les patients souffrant de cardiopathie ischémique $(\mathrm{CI})$, nous avons recruté dans cette étude 120 patients souffrant de ce type d'affection [infarctus aigu du myocarde (IAM) $(n=60)$; angine de poitrine instable (API $(n=60)$ ] et 60 témoins en bonne santé appariés selon l'âge et le sexe. La séroprévalence de I'IgG anti-H.pylori était de 86,7 \% chez les patients IAM, 91,7\% chez les patients API et 58,3\% dans le groupe témoin avec des titres moyens de 33,2 U/ml [erreur-type (ET) 4,76], 57,96 U/ml (ET 7,54) et 25,72 U/ml (ET 4,01) respectivement. La séroprévalence de l'IgG anti-H.pylori dans les groupes de patients était nettement supérieure à celle du groupe témoin. Les taux moyens d'IgG anti-H.pylori dans les groupes IAM et API étaient également nettement supérieurs à ceux du groupe témoin. La séroprévalence et le titre moyen de l'IgG anti-CagA ne présentaient pas de différence significative entre les groupes de patients et le groupe témoin.

'Department of Immunology, Medical School; ' Department of Internal Medicine, Ali-ebne-Abitaleb Hospital, Rafsanjan University of Medical Sciences, Rafsanjan, Islamic Republic of Iran (Correspondence to A. Jafarzadeh:Jafarzadeh14@yahoo.com).

Received: 30/01/09; accepted: 29/03/09 


\section{Introduction}

A number of etiological factors have been determined for development of ischaemic heart disease (IHD). Although there are several major known risk factors for the development of coronary artery disease, about $50 \%$ of patients with this condition do not have any of these risk factors [1]. It has been suggested that inflammatory reactions may play an important role in the pathogenesis of IHD [2] An association between IHD and some infectious agents including Chlamydia pneumoniae, herpes simplex virus (HSV), cytomegalovirus (CMV) and hepatitis $\mathrm{A}$, respiratory tract and dental infection has been reported in some epidemiological studies [2]. However, some prospective studies failed to demonstrate a strong relationship between the presence of IgG antibodies to C. pneumoniae, HSV-1 and CMV and the occurrence of coronary arterial disease [3]. Some investigators also have assessed the relationship between H. pylori and IHD, reporting a strong positive association [4-6] a moderate association [7-10] and even negative association [11-14].

Strains of H. pylori are genetically diverse and have been divided into type I and type II according to the expression or non-expression of cytotoxin-associated gene A (CagA) [15]. CagA has been identified as a virulence marker of H. pylori and the cagA+ strains induce more severe disease and inflammatory response [15]. Since CagA is immunodominant, the detection of serum $\operatorname{IgG}$ to the CagA antigen has been reported as a reliable marker of carriage of cagA+ H. pylori strains [16]. We have recently reported that the seroprevalence of H. pylori in healthy Iranian adults was $67.5 \%$ and in healthy children $46.6 \%$; the prevalence of anti-CagA antibody was $72.8 \%$ in infected adults and $67.4 \%$ in infected children [17].

Elevated levels of C-reactive protein (CRP), fibrinogen, homocysteine, proinflammatory cytokines and antibodies to some heat shock proteins are known to be associated with an increased risk of cardiovascular events [18]. Chronic infections such as $H$. pylori may be behind these changes. However, the role of H. pylori as a risk factor for IHD remains debatable. This study was conducted for the first time to evaluate the seroprevalence of antibody to $H$. pylori and bacterial virulence factor CagA in Iranian patients with IHD to clarify the possible relationships.

\section{Methods}

A total of 120 patients aged 40-65 years with IHD who were admitted to Ali-Ebne-Abitaleb Hospital in Rafsanjan (a city in Kerman province in the southeast of the country) during the period March-December 2007 were enrolled to this cross-sectional, case-controlled study. Sample size was calculated at 50 (using P1 = 90\%; P2 = 60\%; $\alpha=5 \%$; $\beta=10 \%$ ), which was increased to 60 in each group for the actual sample, i.e. 120 patients altogether. Patients were classified into 2 groups according to well-established criteria as having acute myocardial infarction (AMI) or unstable angina (UA). AMI was diagnosed by the presence of 2 of these criteria: prolonged chest pain compatible with AMI, typical ECG changes, elevation of cardiac enzymes. Patients with non-ST elevation were excluded from the study. UA was defined according to Braunwald's classification and all patients had chest pain at rest with definite ischaemic electrocardiographic changes such as ST-segment changes and/or T-wave inversion; all UA patients were in class IIIB according to Braunwald's classification [3]. Exclusion criteria were valvular heart disease, surgery, trauma within the previous month, cardiomyopathy, liver disease, renal failure, malignant diseases, other inflammatory disease (such as septicaemia and pneumonia) and oral anticoagulant therapy. A third sex- and age-matched group with similar geographic and socioeconomic status comprised 60 subjects without any IHD, registered as a control group. The healthy control group was recruited from blood donors at Rafsanjan Blood Transfusion Centre. All patients and controls were residents of Rafsanjan city.

The study was evaluated and approved by the Ethical Committee of Rafsanjan University of Medical Sciences. Informed consent was given and all those recruited had agreed to give blood samples.

Peripheral blood (2-4 mL) was collected from the participants in the 3 groups and the serum separated and stored at $-20^{\circ} \mathrm{C}$. In patients with AMI the serum samples were collected during 3-5 days after admission; in patients with UA they were collected at admission.

\section{Determination of $\boldsymbol{H}$. pylori- specific antibodies in serum}

The serum levels of anti-H. pylori immunoglobulin $G(\operatorname{Ig} G)$ were measured using a commercial enzyme-linked immunosorbent assay (ELISA) (Trinity Biotec, Ireland) according to the manufacturer's guidelines. The results were expressed as $\mathrm{U} / \mathrm{mL}$ and a cut-off value of $5 \mathrm{U} / \mathrm{mL}$ was used to discriminate negative from positive samples.

Serum levels of anti-CagA IgG were also assayed by ELISA using commercial kits (Diagnostic Bioprobes, Italy). The serum concentrations of anti-CagA antibodies were expressed in arbitrary units (Uarb/mL) as no international standard is available. According to the manufacturer's guidelines, acut-offvalue of $5 \mathrm{Uarb} / \mathrm{mL}$ was used to discriminate negative from positive samples. The serum concentrations of anti-H. pylori and anti-CagA antibodies were expressed as mean and standard error (SE).

\section{Statistical analysis}

Differences in variables were analysed using analysis of variance, $t$-test, MannWhitney U test, Kruskal-Wallis test 
and Chi-squared test as appropriate, and $P$-values $<0.05$ were considered significant. All the available data were analysed using SPSS, version 15.0.

\section{Results}

\section{Baseline characteristics}

Baseline characteristics of the participants are shown in Table 1. The patient and control groups were similar in age and male/female ratio, but patients had significantly higher prevalence of classic risk factors for IHD (hypertension, dyslipidaemia and diabetes) compared with the control group.

\section{Anti-H. pylori IgG seropositivity}

The overall seroprevalence of antiH. pylori IgG was $89.2 \%$ among patients with IHD and 58.3\% among healthy controls with mean titre $45.58 \mathrm{U} / \mathrm{mL}$ (SE 4.58) and $25.72 \mathrm{U} / \mathrm{mL}$ (SE 4.01) respectively. The prevalence of antiH. pylori $\operatorname{IgG}$ was significantly higher in IHD patients compared to the control group $(P<0.0001)$. The mean titre of anti-H. pylori antibodies in the IHD group was significantly higher than that observed in the control group $(P<0.01)$ (Table 2). The seropositivity rate of anti-H. pylori antibody was $86.7 \%$ and $91.7 \%$ in the AMI and UA groups with mean titre of $33.2 \mathrm{U} / \mathrm{mL}$ (SE 4.76) and $57.96 \mathrm{U} / \mathrm{mL}$ (SE 7.54) respectively. The seroprevalence of anti-H. pylori antibodies in AMI and UA groups was also significantly higher compared to the control group $(P<0.0001)$. The mean titre of anti-H. pylori antibodies in AMI and UA groups was significantly higher than that observed in control group $(P<0.05$ and $P<0.001$ respectively $)$. The seroprevalence of anti-H. pylori was similar in patients with AMI and UA. No significant difference was observed between the AMI and UA groups regarding the mean titre of anti-H. pylori antibodies (Table 2).

\section{Anti-CagA seropositivity}

The overall seroprevalence of anti-CagA IgG was $60.7 \%$ in $H$. pylori-infected patients with IHD and $65.7 \%$ in infected asymptomatic healthy subjects; mean titres were $37.68 \mathrm{Uarb} / \mathrm{mL}$ (SE 8.35) and $16.84 \mathrm{Uarb} / \mathrm{mL}$ (SE 2.88) respectively. There was no significant difference between IHD and control groups regarding the prevalence of anti-CagA antibodies. There was no significant difference between IHD and control groups regarding the mean titre of serum anti-CagA antibodies, although this parameter was higher in the IHD group in comparison to asymptomatic healthy subjects. The seropositivity rate of antiCagA antibody was $55.8 \%$ and $65.5 \%$ in H. pylori-infected patients with AMI and UA respectively; mean titres were 42 Uarb/mL (SE 15.42) and 33.61 Uarb/ $\mathrm{mL}$ (SE 7.32) respectively (Table 2).

Statistical analysis showed that the differences for both seroprevalence and mean titre of anti-CagA antibodies were not significant between the AMI and UA groups compared to the control group. The prevalence and the mean titre for anti-CagA antibodies were similarly expressed in patients with AMI and UA (Table 2).

\section{Discussion}

In this study the seroprevalence of anti-H. pylori IgG and the mean titre of anti-H. pylori antibodies were significantly higher in patients with IHD compared to the healthy control group. The seropositivity rate for $H$. pylori infection varies greatly between studies (Table 3 ). Moreover, the association of $H$. pylori with IHD may also differ between countries or even within a country. The discrepancies may be attributed largely to differences in age, socioeconomic status, race and ethnic background. Moreover, different inclusion criteria of patients and controls used in the various studies, differences in the distribution of traditional risk factors of IHD and genetic heterogeneities of H. pylori may account for some differences. Accordingly, the results of one study may not necessarily apply to other populations, even within the country.

H. pylori infection might participate in IHD pathogenesis via direct or indirect effects. The presence of $H$. pylori DNA has been demonstrated in the aortic tissues and atherosclerotic plaques of the majority patients with coronary heart disease, which could be an important indication of the direct role of bacteria in the pathogenesis of disease [19]. Accordingly, H. pylori can directly provoke inflammation within the atherosclerotic plaques.

\begin{tabular}{lcccc}
\hline Table 1 Baseline characteristics of patient and control groups & & & \\
\hline Characteristic & $\begin{array}{c}\text { Acute myocardial infarction } \\
(\boldsymbol{n}=\mathbf{6 0})\end{array}$ & $\begin{array}{c}\text { Unstable angina } \\
(\boldsymbol{n}=\mathbf{6 0})\end{array}$ & $\begin{array}{c}\text { Controls } \\
(\boldsymbol{n}=\mathbf{6 0})\end{array}$ & $\begin{array}{c}P \text {-value } \\
\text { Mean (SEM) age (years) }\end{array}$ \\
\hline $54.6(9.7)$ & $55.8(9.6)$ & $52.98(8.7)$ & NS \\
Sex (men/women) (No.) & $39 / 21$ & $35 / 25$ & $33 / 27$ & NS \\
Hypertension (No.) & 7 & 8 & 0 & 0.01 \\
Dyslipidaemia (No.) & 10 & 6 & 0 & 0.01 \\
Diabetes mellitus (No.) & 7 & 9 & 0 & 0.01 \\
\hline
\end{tabular}

${ }^{a}$ Comparing all patients with ischaemic heart disease and healthy control group.

SEM = standard errof of the mean. 


\begin{tabular}{|c|c|c|c|c|}
\hline Variable & Control group & IHD group & AMI group & UA group \\
\hline Seroprevalence of anti-H. pylori (\%) & 58.3 & $89.2^{* * *}$ & $86.7^{* * *}$ & $91.7^{* * *}$ \\
\hline Serum anti-H. pylori (U/mL) [Mean (SE)] & $25.72(4.01)$ & $45.58^{* *}(4.58)$ & $33.2 *(4.76)$ & $57.96^{* * *}(7.54)$ \\
\hline Serum anti-CagA (Uarb/mL) [Mean (SE)] & $16.84(2.88)$ & $37.68(8.35)$ & $42(15.42)$ & $33.61(7.32)$ \\
\hline
\end{tabular}

${ }^{*} P<0.05 ;{ }^{* *} P<0,01 ;{ }^{* *} P<0.001$ compared to control group

$A M I=$ acute myocardial infarction .

$\cup A=$ unstable angina

Our results showed no significant differences between patient and control groups regarding the prevalence of serum anti-CagA antibodies, which indicates that CagA-positive strains were not more related to IHD in comparison to CagA-negative strains. However, the results of a systematic meta-analysis confirm the hypothesis that infection with CagA-seropositive strains is significantly associated with susceptibility to coronary heart disease [20]. The controversial results of some studies regarding the association of CagA status of H. pylori with IHD have been summarized in Table 4. It has also been reported that there is wide geographical variation in the genotype of CagA+ strains [24]. Moreover, the polymorphisms in genes encoding for some cytokines such as IL- 1 , TNF- $\alpha$ and IFN- $\gamma$ have been associated with $H$. pylori-related diseases such as gastric cancer and peptic ulcer [25]. Accordingly, it seems that both host and bacterial factors may account for these differences. Further studies on the interaction between $H$. pylori and the host genotype, which in turn could determine the intensity of the inflammatory responses, may explain the development of IHD in some H. pylori-infected subjects.

Consistent with our findings in the present study, we recently observed that serum concentrations of hs-CRP were not affected by the expression of bacterial CagA virulence factor [26]. However, in our previous study in the same population, an important association was observed between infection with CagA-positive H. pylori strains and

\begin{tabular}{llllc}
\hline $\begin{array}{l}\text { Table } 3 \text { Comparison of the association of Helicobacter pylori and ischaemic heart } \\
\text { disease (IHD) in selected studies }\end{array}$ & & & \\
\hline Country & H. pylori seropositivity & P-value & Reference \\
& IHD & Controls & & \\
India & 98 & 57 & 0.001 & 4 \\
& 77 & 43 & 0.001 & 4 \\
Turkey & 58 & 53 & NS & 11 \\
& 60.2 & 57.7 & NS & 12 \\
Greece & 78.8 & 58.3 & 0.05 & 7 \\
& 77 & 68 & NS & 13 \\
Italy & 55.1 & 39.6 & 0.05 & 8 \\
& 78.3 & 56.2 & 0.05 & 9 \\
& 84.7 & 61.8 & 0.0001 & 5 \\
Japan & 78.7 & 76.2 & NS & 14 \\
& 58.7 & 43.3 & 0.009 & 6 \\
Islamic Republic of Iran & 87.9 & 66.7 & 0.05 & 10 \\
\hline
\end{tabular}

NS = not significant peptic ulcer [27], which indicate that the role of the CagA-positive strains may differ in peptic ulcer and IHD pathogenesis.

We have demonstrated that the mean titre of anti-H. pylori antibodies in patients with IHD was significantly higher than that observed in a control group. Moreover, the mean serum levels of anti-CagA antibodies were higher in patients than controls, but the differences were not statistically significant. Recently, cross-reactivity between rabbit serum with high levels of anti-H. pylori and antigens from atherosclerotic carotid arteries has been demonstrated [28]. It has been also shown that antiCagA antibodies are capable of reacting with both bacterial CagA and proteins present in the wall of arteries, providing evidence of molecular mimicry between CagA and vascular antigens [29]. Accordingly, it has been suggested that CagA-positive strains of H. pylori may contribute to the destabilization of coronary atherosclerotic plaques in some patients with acute coronary syndrome. From these findings, it seems that both anti-H. pylori and anti-CagA antibodies may have an important role in the pathogenesis of IHD.

Further prospective studies are needed to assess the relationship between exposure to H. pylori and subsequent risk of ischaemic heart disease. Because H. pylori infection may be easily eradicated by specific treatments, the accurate definition of this new risk factor may lead to the design of possible novel strategies for the prevention of ischaemic heart disease. Recent studies have highlighted the importance of the 


\begin{tabular}{|c|c|c|c|c|}
\hline \multirow{2}{*}{ Country } & \multicolumn{2}{|c|}{ Anti-CagA seropositivity (\%) } & \multirow[t]{2}{*}{$P$-value } & \multirow[t]{2}{*}{ Reference } \\
\hline & \multicolumn{2}{|c|}{ IHD Controls } & & \\
\hline \multirow{2}{*}{ Italy } & \multirow{2}{*}{$\begin{array}{l}33.8 \\
71.4\end{array}$} & & 0.0001 & \multirow{2}{*}{$\begin{array}{r}5 \\
14\end{array}$} \\
\hline & & 52.4 & 0.03 & \\
\hline \multirow{2}{*}{ Japan } & 72.7 & 57.6 & 0.05 & 10 \\
\hline & 27.9 & 21.7 & NS & 21 \\
\hline \multirow{3}{*}{$\begin{array}{l}\text { Germany } \\
\text { Poland } \\
\text { United Kingdom } \\
\text { Islamic Republic of Iran }\end{array}$} & 81 & 85 & NS & 22 \\
\hline & 52 & 43 & 0.023 & 23 \\
\hline & 60.7 & 65.7 & NS & Present study \\
\hline
\end{tabular}

association the of number of pathogens (pathogen burden) by which an individual has been infected with IHD [30]. Accordingly, the application of broader strategies, not only against $H$. pylori but also against C. pneumoniae and other infectious organisms such as those causing chronic bronchitis and periodontitis, may be considered for the prevention of ischaemic heart disease.

\section{References}

1. Beaglehole R, Magnus P. The search for new risk factors for coronary heart disease: occupational therapy for epidemiologists? International Journal of Epidemiology, 2002, 31:1117-1122.

2. Mahmoudi M, Curzen N, Gallagher PJ. Atherogenesis: the role of inflammation and infection. Histopathology, 2007, 50:535-546.

3. Ridker PM, Genest G, Libby P. Risk factors for atherosclerotic disease in Braunwald, Textbook of heart disease, 6th ed. Philadelphia, WB Saunders, 2001:1028-1031.

4. Jha HC, Prasad J, Mittal A. High immunoglobulin A seropositivity for combined Chlamydia pneumoniae, Helicobacter pylori infection, and high-sensitivity C-reactive protein in coronary artery disease patients in India can serve as atherosclerotic marker. Heart Vessels, 2008, 23(6):390-6.

5. Pellicano R et al. Infection by Helicobacter pylori and acute myocardial infarction. Do cytotoxic strains make a difference? New Microbiology, 2002, 25(3):315-321.

6. Kinjo $\mathrm{K}$ et al. [Osaka Acute Coronary Insufficiency Study (OACIS) Group]. Prevalence of Helicobacter pylori infection and its link to coronary risk factors in Japanese patients with acute myocardial infarction. Circulation Journal, 2002, 66(9):805-810.

7. Vcev A et al. Helicobacter pylori infection and coronary artery disease. Collegium Antropologium, 2007, 31(3):757-60.

8. Nikolopoulou A et al. Common community infections and the risk for coronary artery disease and acute myocardial infarction: evidence for chronic over-expression of tumor necrosis factor alpha and vascular cells adhesion molecule-1. International journal of cardiology, 2008, 12,130(2):246-50.

9. Andreica $V$ et al. The prevalence of anti-Helicobacter pylori antibodies in the patients with ischemic heart disease. Romanian Journal of Internal Medicine, 2004, 42(1):183-9.

10. Miyazaki M et al. Is Helicobacter pylori infection a risk factor for acute coronary syndromes? Journal of Infection, 2006, 52(2):86-91.

11. Chaudhury A et al. Seroprevalence of IgG antibodies to Chlamydia pneumoniae and Helicobacter pylori among coronary heart disease patients and normal individuals in South Indian population. Indian Journal of Pathology and Microbiology, 2004, 47(3):433-4.

12. Kanbay $\mathrm{M}$ et al. Helicobacter pylori seroprevalence in patients with coronary artery disease. Digstive Diseases and Sciences, 2005, 50(11):2071-4.
13. Sotiropoulos A et al. Seropositivity to Chlamydia pneumoniae or Helicobacter pylori and coronary artery disease. International Journal of Cardiology, 2006, 109(3):420-421.

14. Lenzi $\mathrm{C}$ et al. H. pylori infection and systemic antibodies to CagA and heat shock protein 60 in patients with coronary heart disease. World Journal of Gastroenterology. 2006, 12(48):7815-7820.

15. Figueiredo C, Marchado JC, Yamaoka Y. Pathogenesis of Helicobacter pylori Infection. Helicobacter, 2005,10(Suppl. 1):14-20.

16. Jimenze F et al. Seroprevalence of Helicobacter pylori antiCagA antibodies and its relationship with epidemiologic factors in Santa Fe. Acta Gastroenterologica Latinoamericana, 2004, 34:16-20.

17. Jafarzadeh A, Rezayati MT, Nemati M. Specific serum immunoglobulin G to H. pylori and CagA in healthy children and adults (south-east of Iran). World Journal of Gastroenterology. 2007, 13:3117-21.

18. Manolakis A, Kapsoritakis AN, Potamianos SP. A review of the postulated mechanisms concerning the association of Helicobacter pylori with ischemic heart disease. Helicobacter, 2007, 12:287-297.

19. Reszka E et al. Detection of infectious agents by polymerase chain reaction in human aortic wall. Cardiovascular Pathology, 2008, 17(5):297-302.

20. Zhang S et al. Cytotoxin-associated gene-A-seropositive virulent strains of Helicobacter pylori and atherosclerotic diseases: a systematic review. Chinese Medical Journal, 2008, 121(10):946-951.

21. Koenig W et al. Infection with Helicobacter pylori is not a major independent risk factor for stable coronary heart disease: lack of a role of cytotoxin-associated protein A-positive strains and absence of a systemic inflammatory response. Circulation, 1999, 100(23):2326-2331.

22. Chmiela M et al. A link between Helicobacter pylori and/or Chlamydia spp. infections and atherosclerosis. FEMS Immunology and Medical Microbiology, 2003, 36(3):187-192.

23. Singh RK et al. Prospective analysis of the association of infection with CagA bearing strains of Helicobacter pylori and coronary heart disease. Heart, 2002, 88(1):43-6.

24. Azuma T. Helicobacter pylori CagA protein variation associated with gastric cancer in Asia. Journal of Gastroenterology, 2004, 39(2):97-103.

25. Basso D, Plebani M. H. pylori infection: bacterial virulence factors and cytokine gene polymorphisms as determinants of 
infection outcome. Critical Reviews in Clinical Laboratory Sciences, 2004, 41:313-337

26. Jafarzadeh A, Hasanshahi GH, Nemati M. Serum levels of highsensitivity C-reactive protein (hs-CRP) in Helicobacter pyloriinfected peptic ulcer patients and its association with bacterial CagA virulence factor. Digstive Diseases and Sciences, 2009, 54(12):2612-2616.

27. Jafarzadeh A, Salari M. Seroprevalence of anti-Helicobacter pylori and anti-CagA antibodies in peptic ulcer and healthy subjects in the city of Rafsanjan. Journal of Research in Medical Sciences, 2006, 11:285-291.
28. Cammarota $\mathrm{G}$ et al. Is there mimicry between arteriosclerotic lesions and H. pylori antigens? Clinical Biochemistry. 2000, 33:419-421.

29. Franceschi $\mathrm{F}$ et al. Cross-reactivity of anti-CagA antibodies with vascular wall antigens: possible pathogenic link between Helicobacter pylori infection and atherosclerosis. Circulation, 2002, 106:430-434.

30. Steptoe A et al. Socioeconomic status, pathogen burden and cardiovascular disease risk. Heart, 2007, 93(12):1567-1570.

\section{Fact sheet $\mathrm{N}^{\circ} 317$ Cardiovascular diseases (CVDs):} http://www.who.int/mediacentre/factsheets/fs317/en/index.html

- CVDs are the number one cause of death globally: more people die annually from CVDs than from any other cause.

- An estimated 17.1 million people died from CVDs in 2004, representing 29\% of all global deaths. Of these deaths, an estimated 7.2 million were due to coronary heart disease and 5.7 million were due to stroke.

- Low- and middle-income countries are disproportionally affected: $82 \%$ ofCVD deaths take place in low- and middleincome countries and occur almost equally in men and women.

- By 2030, almost 23.6 million people will die from CVDs, mainly from heart disease and stroke. These are projected to remain the single leading causes of death. The largest percentage increase will occur in the Eastern Mediterranean Region. The largest increase in number of deaths will occur in the South-East Asia Region. 